\title{
Complicated hepatic and pulmonary hydatid cyst and hospital post-surgical stay in patients intervened in two hospitals of Peru, 2000-20 I I
}

\begin{abstract}
Background: Echinococcosis is a parasitic zoonosis of high prevalence in some regions of Peru, and the treatment of choice in advanced stages is surgery, which leads to prolonged hospital stays. In this sense, the research aimed to associate the number of days of postsurgical hospitalization and the presence of hydatid cyst complication.

Methods: Cross-sectional study with a population consisting of patients diagnosed with echinococcosis in two hospitals in Peru between 2000 and 2011. A primary database was used, generated from the exploration of medical records of individuals who underwent surgery. Data were recorded on the number of days of post-surgical hospitalization, complication of hydatid cyst, affected organ, and type of cyst, number, diameter and volume of cysts, type of surgery, pre- surgical and post-surgical anthelmintic prophylaxis, hospital, age and sex. The association was evaluated by the exponentiated coefficient adjusted in a negative binomial regression.
\end{abstract}

Results: We evaluated 655 patients constituted by women in $53.6 \%$, and the average age was $32.3 \pm 18.6$ years. Complication of hydatid cyst occurred in $54.2 \%$, while the median post-surgical hospital stay was 9 days, and this did not present significant differences according to pre-surgical prophylaxis and age groups. There was no significant association between the number of days of post-surgical hospitalization and the complication of the hydatid cyst (e ${ }^{\text {coef: }}$ 1.17, CI95\%: 1.00-1.39); However, post-surgical prophylaxis and care according to Hospital did generate significant differences.

Conclusion: There is no significant association between the complication of the hepatic and pulmonary hydatid cyst and the number of days of post-surgical hospitalization

Keywords: complicated hydatid cyst, surgery, hospital stay
Volume 4 Issue I - 2020

\author{
Jaime Rosales Rimache,' Saúl Santivañez \\ Salazar ${ }^{2}$ \\ 'Occupational Health, School of Public Health and \\ Administration, Universidad Peruana Cayetano Heredia, Peru \\ IInternational Health, Global Health Center, Universidad \\ Peruana Cayetano Heredia, Peru
}
Correspondence: Jaime Alonso Rosales Rimache, MSc. Faculty of Public Health and Administration, Universidad Peruana Cayetano Heredia, Av. Honorio Delgado 430, San Martín de Porres I5102, Lima, Perú, Tel + 5 I I 944457898 , Email jaime.rosles@upch.pe

Received: January 08, 2020 | Published: January 27, 2020
Abbreviations: CE, cystic echinococcosis; GLM, generalized linear model; SIDISI, decentralized system of information and monitoring of research; IRB-UPCH, institutional review board from Universidad peruana Cayetano Heredia

\section{Introduction}

Echinococcosis is an worldwide neglected infectious disease, which causes serious problems in human and animal health, ${ }^{1}$ and is caused by infection with larvae of Echinococcus granulosus, E. multilocularis, E. vogeli or E. oligarthrus, with different clinical presentations (hepatic and pulmonary, mainly), and serious complications due to the presence of the hydatid cyst, which varies in number, size and location. ${ }^{2}$ In Peru, human cystic echinococcosis (CE) has a high prevalence in rural areas of the central Andes ${ }^{3-5}$ and some coastal regions ${ }^{6}$ and its etiology is restricted only to E. granulosus. ${ }^{7}$ The diagnosis of CE is supported by clinical findings, and identification of the hydatid cyst by imaging studies such as ultrasonography, radiography, tomography and/or magnetic resonance; and confirmation is established by immunological and molecular analyzes, such as ELISA (enzymelinked immunosorbent assay) and immunoblot. ${ }^{2}$ However, the study by ultrasonography and tomography allows classifying the hydatid cyst in 5 categories: CE1, CE2, CE3, CE4 and CE5. ${ }^{8}$ The classification of hydatid cyst is fundamental for the choice of a treatment, which usually combines pharmacological and surgical measures. ${ }^{9}$ Surgical treatment is an option that must be carefully evaluated, depending on the presence or absence of complicated hydatid cyst, multiple location and size. ${ }^{8}$ Surgical procedures can be radical (total removal of the hydatid cyst and removal of its outer layers, in some cases even with loss of liver or lung tissue) or conservatives (evacuation of hydatid cyst content and removal of its internal layers). In both cases, risk of mortality and postoperative complications are imminent, even when there are options of equal or greater efficacy and safety, such as PAIR (puncture-aspiration-injection and re-aspiration). ${ }^{9,10}$

Taking into account that surgical treatment in Peru is the most viable option for $\mathrm{CE}$ in advanced stages, it should be considered that there is a risk of postoperative complications that prolong the hospital stay of the patient, even more if there is a complicated hydatid cyst, which according to evidence, it can occur in up to half of people with hepatic $\mathrm{CE}$ with postoperative morbidity and recidivism of infection after 8 years of intervention; ${ }^{11}$ although depending on the technique applied, it is evident that radical surgery generates fewer complications, reinfections and biliary fistulas, than conservative surgery. ${ }^{12,13}$ The presence of complicated hydatid cyst generates a greater total burden of disease in the patient, which in turn conditions years of life with disability even when the patient can receive surgical treatment; and in addition, higher costs to health systems. ${ }^{14}$ A tendency to decrease hospital stay has been established, probably due to early diagnosis, ${ }^{15,16}$ and in other cases to health education. ${ }^{17}$ In addition, possible factors that affect the development of $\mathrm{CE}^{18}$ and hospital stay ${ }^{19}$ must be considered. ${ }^{19}$

The hospital stay due to surgical interventions in patients with 
confirmatory diagnosis of echinococcosis can vary considerably, depending on the stage and progression of the disease,,${ }^{8,20}$ and especially in the presence of complication due to rupture and/or infection of the hydatid cyst. Some authors have indicated that early diagnosis of echinococcosis is the most important way to reduce complications, ${ }^{21}$ and therefore surgical treatment and hospital stay, which generate three times the cost of health services, compared to those who receive only pharmacological treatment and without hospitalization. ${ }^{22}$ In fact, the expenses for hospital stay due to human CE are the highest in comparison to similar parasitosis such as fasciolosis or neurocysticercosis. ${ }^{23}$ The importance of assessing hospital postsurgical stay in people with complicated hydatid cyst may result in a reliable indicator to show that the stages of disease condition the length of hospital stay, in addition to considering various intervening factors (cyst characteristics, albendazol treatment, type of surgery and others); therefore, be useful for the prioritization of activities that are aimed at promoting and strengthening primary prevention measures through early diagnosis with technologies that are easy to implement and health education in populations at risk of E. granulosus infection.

\section{Materials and methods}

\section{Study design}

Cross-sectional study that used historical data from a primary base generated from the exploration of medical records of patients with CE who were treated surgically during the period 2000 and 2011; which aimed to determine the cumulative incidence of twelve years of new cystic lesions in patients with hepatic echinococcosis who were treated surgically and assess their impact on the quality of life of the affected subjects.

\section{Study population}

The population consisted of all the data obtained from the examination of medical records that refers patients diagnosed with CE (based on ultrasound and/or tomographic evaluation) and who underwent surgery at Dos de Mayo Hospital from Lima and Daniel Alcides Carrión Hospital from Huancayo Both hospitals were selected in the primary study (after acceptance of the management of each institution), based on their geographical and epidemiological characteristics; since Lima and Junín are two of the departments that present a greater burden of attention in relation to $\mathrm{CE}$ and surgical interventions (approximately 20 procedures per year for each hospital). Both hospitals maintain the level of care III according to the organic structure of the Ministry of Health of Peru.

We excluded those records that did not have an image evaluation (ultrasound and / or tomography) before the surgical intervention, and the presence of implausible data, after an additional and exhaustive review of the clinical history. For the calculation of the statistical power in the study, the Poisson regression model was used ${ }^{24}$ for the dependent variable (number of days of post-surgical hospitalization) in an independent variable (presence of complicated hydatid cyst), normally distributed. The information reported by Herrador et al. ${ }^{15}$ was assumed ${ }^{15}$ (number of days of hospitalization in hepatic and pulmonary echinococcosis) with a mean $=11$ days and standard deviation=15 days, using a sample of 655 observations (database of the primary study). The power obtained was $100 \%$, at a significance level of 0.05 , to detect a response rate of at least 1.30 due to a change in a unit. The reference rate was 1.0 and the average exposure time of 1.0. The sample size was adjusted, since it was expected that a multiple regression of the variable of interest in the other covariates in the Poisson regression would have an R-square of 0.90. The statistical power calculation was made with the PASS software version 11.0.

\section{Variables}

Variable outcome: number of days of post-surgical hospitalization

It was the estimated time as the difference from the date of the surgical intervention due to the presence of hydatid cyst (s) in the liver and / or lung, until discharge from hospital, which was evidenced by administrative documents issued by each hospital. The variable was treated as a discrete and categorical number.

\section{Variable exposure: complicated hydatid cyst}

It was the presence of infection and / or rupture associated with the hydatid cyst, which was evidenced in situ during the surgical intervention. The variable was dichotomous (presence / absence), and subcategorized those hydatid cysts that had complication (infection / rupture).

\section{Co-variables}

We obtained data on the affected organ, type of cyst, number, diameter and volume of cysts, type of surgery, pre-surgical and postsurgical anthelmintic prophylaxis, hospital, age and sex.

\section{Procedures and techniques}

A clinical record designed to collect demographic, epidemiological and clinical data of each patient undergoing surgery was used. The designed instrument assumed the face validity, ${ }^{25}$ considering that it was applied to collect data from medical records, whose information was objective and was based on a confirmatory diagnosis with support of images and laboratory tests. The file was filled by qualified personnel in double digitation to avoid transcription errors.

\section{Ethical considerations}

This research was registered in the Decentralized System of Information and Monitoring of Research (SIDISI), and evaluated by the Institutional Review Board from Universidad Peruana Cayetano Heredia (IRB-UPCH).

\section{Data analysis}

The study variables were presented in a descriptive way, the numerical variables expressed as measures of central tendency and dispersion and the categorical ones in absolute frequencies and proportions. The median of hospitalization times was compared according to the presence or absence of a complicated hydatid cyst using the nonparametric Mann-Whitney test, taking as a significant difference a value of $\mathrm{p}<0.05$. The hospitalization times were also contrasted according to the study co-variables, using the KruskallWallis test for cases where there were more than two categories and taking as a significant difference a value of $\mathrm{p}<0.05$. The multivariate analysis was using the negative binomial regression model, after evaluation of data dispersion by graphical method, comparison of mean and variance, and the goodness-of-fit test. The adjustment was made through variables such as the characteristics of the hydatid cyst (number, size and volume), prophylactic treatment (pre- and postsurgical), type of surgery and hospital; which were selected by the likelihood ratio test. The exponentiated value of the coefficients was 
used as a measure to estimate the average adjusted for the effect of the rest of the covariates, finally using the generalized linear model (GLM). The data analysis was performed using the statistical package Stata 14.0. There were incomplete records in relation to the dependent and independent variable, which were excluded from the study; however, these did not exceed $10 \%$ of the total records eligible for the secondary study.

\section{Results}

The study population consisted of 655 people (more than half women) with confirmatory diagnosis of echinococcosis, who were scheduled for surgery where it was found that more than halfpresented complication of the hydatid cyst, whose cause was due to cyst infection. (61.4\%) and breakage (38.6\%). Table 1 shows that the number of days of post-surgical hospitalization shows high dispersion, as well as the number, diameter and volume covariates of hydatid cysts; In addition, the proportion of patients with complicated hydatid cyst is similar to those with uncomplicated hydatid cyst.

Table I Characteristics of patients with echinococcosis surgically operated in two hospitals in Peru, 2000 and 20II

\begin{tabular}{|c|c|}
\hline Characteristics & $\mathbf{N}(\%)$ \\
\hline \multicolumn{2}{|l|}{ Sex } \\
\hline Male & $304(46.4)$ \\
\hline Female & $35 I(53.6)$ \\
\hline Age (years)* & $32.3 \pm 18.6$ \\
\hline \multicolumn{2}{|l|}{ Hospital } \\
\hline Dos de Mayo, Lima & $|7|(26.1)$ \\
\hline Daniel A. Carrión, Huancayo & $484(73.9)$ \\
\hline \multicolumn{2}{|l|}{ Affected organ } \\
\hline Lung & $342(52.2)$ \\
\hline Liver & $313(47.8)$ \\
\hline Number of cysts $\dagger$ & $\mathrm{I}(\mathrm{I})$ \\
\hline Diameter of cyst $(\mathrm{cm}) \dagger$ & $4(3)$ \\
\hline Total volume of cysts $(\mathrm{mL}) \dagger$ & $407.7(838.5)$ \\
\hline \multicolumn{2}{|l|}{ Type of surgery } \\
\hline Conservative & $515(78.6)$ \\
\hline Radical & $140(2 \mid .4)$ \\
\hline \multicolumn{2}{|c|}{ Pre-surgical prophylaxis with albendazole } \\
\hline No & $245(37.5)$ \\
\hline Yes & $409(62.5)$ \\
\hline \multicolumn{2}{|c|}{ Post-surgical prophylaxis with albendazole } \\
\hline No & $296(45.3)$ \\
\hline Yes & $358(54.7)$ \\
\hline \multicolumn{2}{|l|}{ Complicated hydatid cyst } \\
\hline No & $300(45.8)$ \\
\hline Yes & $355(54.2)$ \\
\hline Hospital post-surgical stay (days) $\dagger$ & $9(6)$ \\
\hline
\end{tabular}

*Mean \pm standard deviation

†Median (interquartile range)
Table 2 shows the hypothesis contrast of the number of days of postsurgical hospitalization according to the covariates and complication of the hydatid cyst. It is observed that there are significant differences $(p<0.05)$ due to the presence of complicated hydatid cyst, in addition to other covariates such as sex, hospital, type of surgery, post-surgical prophylaxis, number, volume and diameter of the cysts.

Table 2 Factors associated with hospital post-surgical stay in patients with echinococcosis operated on in two hospitals in Peru, 2000 and 2011

\begin{tabular}{|c|c|c|}
\hline \multirow[t]{2}{*}{ Variables } & \multicolumn{2}{|c|}{ Hospital post-surgical stay (days) } \\
\hline & Median (IQR) & $\mathbf{p}$ \\
\hline \multicolumn{3}{|l|}{ Sex } \\
\hline Male & $10(8)$ & $0.026 *$ \\
\hline Female & $9(6)$ & \\
\hline \multicolumn{2}{|l|}{ Affected organ } & $0.036+$ \\
\hline Lung & $10(7)$ & \\
\hline Liver & $9(6)$ & \\
\hline \multicolumn{2}{|l|}{ Hospital } & $0.002+$ \\
\hline $\begin{array}{l}\text { Daniel A. Carrión, } \\
\text { Huancayo }\end{array}$ & $8(4)$ & \\
\hline Dos de Mayo, Lima & $10(8)$ & \\
\hline \multicolumn{2}{|l|}{ Type of surgery } & $<0.001 *$ \\
\hline Conservative & $9(5)$ & \\
\hline Radical & II (8) & \\
\hline \multicolumn{2}{|c|}{ Pre-surgical prophylaxis with albendazole } & $0.148^{*}$ \\
\hline No & $10(8)$ & \\
\hline Yes & $9(6)$ & \\
\hline \multicolumn{2}{|c|}{ Post-surgical prophylaxis with albendazole } & $<0.001 *$ \\
\hline No & $10(10)$ & \\
\hline Yes & $9(5)$ & \\
\hline \multicolumn{2}{|l|}{ Age group } & $0.185+$ \\
\hline$<18$ years & $9(6)$ & \\
\hline $18-35$ years & $9(6)$ & \\
\hline $36-60$ years & $10(8)$ & \\
\hline$>60$ years & $10(5.5)$ & \\
\hline \multicolumn{2}{|l|}{ Number of cysts } & $0.001 *$ \\
\hline One & $9(5)$ & \\
\hline More than one & $10(9)$ & \\
\hline \multicolumn{2}{|l|}{ Diameter of cyst } & $0.041^{*}$ \\
\hline$\leq 4 \mathrm{~cm}$ & $9(6)$ & \\
\hline$>4 \mathrm{~cm}$ & $9(8)$ & \\
\hline \multicolumn{2}{|c|}{ Total volume total of cysts } & $0.00 I^{*}$ \\
\hline$\leq 500 \mathrm{~mL}$ & $9(5)$ & \\
\hline$>500 \mathrm{~mL}$ & $10(8)$ & \\
\hline \multicolumn{2}{|c|}{ Complicated hydatid cyst } & $0.004^{*}$ \\
\hline No & $8(5)$ & \\
\hline Yes & $10(8)$ & \\
\hline
\end{tabular}

"Mann-Whitney; 'Kruskal-Wallis; IQR, interquartile range 
Table 3 shows that the average in the number of days of postsurgical hospitalization in those who had hydatid cyst complication is $20 \%$ higher than those with uncomplicated hydatid cyst, with a non-significant value (e $\mathrm{e}^{\text {coef: }} 1.17$, CI95\%: 1.00-1.39)) and adjusted by confounding variables. However, the hospital where the surgical intervention was performed and the post-surgical prophylaxis are factors that were independently associated with the number of days of post-surgical hospitalization.

Table 3 Factors independently associated with the number of days of postsurgical hospitalization in patients with CE operated in two hospitals in Peru, period 2000 and 2011

\begin{tabular}{ccccccc}
\hline Variables & \multicolumn{2}{c}{ Bivariate analysis } & \multicolumn{3}{c}{ Multivariate analysis* } \\
& $\mathrm{e}^{\text {coef }}$ & Cl 95\% & p & e $^{\text {coef }}$ & Cl 95\% & P \\
\hline
\end{tabular}

Complicated hydatid cyst

\begin{tabular}{lllllll} 
No & Ref. & \multicolumn{5}{c}{ Ref. } \\
Yes & 1.2 & $1.02-1.41$ & 0.03 & 1.17 & $1.00-1.39$ & 0.06
\end{tabular}

Hospital

Daniel A.

Carrión, Hyo

Ref.

Ref.

Dos de Mayo,

Lima

I.35

I.13-1.62

1.28

I.04-I.57 0.02

Type of surgery

ConservativE Ref.

Ref.

Radical

I.I4 0.94-I.38

0.19

1.13

$0.91-1.39 \quad 0.26$

Pre-surgical prophylaxis with

albendazole

No

Ref.

Ref.

Yes

$0.91 \quad 0.77-1.07 \quad 0.24$

$0.76-1.07 \quad 0.24$

Pre-surgical prophylaxis with

albendazole

No

Ref.

Ref.

Yes

0.74

0.63-0.87

$0.67-0.96 \quad 0.0$

Number of cysts

One

Ref.

More than

one

1.22

$\mathrm{I} .03-\mathrm{I} .43$

Ref.

Diameter of cyst

$\leq 4 \mathrm{~cm}$

Ref.

Ref.

$>4 \mathrm{~cm}$

I. 12

0.96-I.3।

0.16

0.94

$0.7 \mid-1.25$

0.68

Total volume total of cysts

$\leq 500 \mathrm{~mL} \quad$ Ref.

Ref.

$>500 \mathrm{~mL}$

1.2

I.04-I.43

\section{Discussion}

The findings show that hospitalization time is a variable that has a high dispersion, in comparison to the rest of variables that maintain similar proportions among their categories. It is also observed that the complication of the hydatid cyst is independently associated with the time of hospitalization, in such a way that the rate of hospitalization time in those with complicated hydatid cyst is $20 \%$ more than the rate of those who suffer from uncomplicated hydatid cyst. It was also observed that the number and volume of cysts significantly influence the number of days of hospitalization, so much so that those who had more than one cyst and volume greater than $500 \mathrm{~mL}$ presented $22 \%$ more in the number of days of hospitalization in comparison to those who had a single cyst and volume less than $500 \mathrm{~mL}$.

The number of days of post-surgical hospitalization depends on several variables, being one of the most important, the presence of complicated hydatid cysts, which are generated by infection or rupture of them and that can be evidenced by image evaluation and in situ during the surgical intervention. ${ }^{26}$ Our findings are similar to that reported by Kuzuku et al. who found significant differences $(\mathrm{p}<0.05)$ in hospitalization time in patients with complicated hydatid disease $(n=34)$ and uncomplicated $(n=33)$, with averages of $21(7-74)$ and 10 (7-19) days, respectively; even when they had limitations with respect to the sample size ${ }^{19}$ and they considered time from the internment of each individual. The average hospitalization time was also estimated by Herrador et al. ${ }^{15}$ who reported 11 days $(0-251)$ and $10(0-113)$ for hepatic and pulmonary CE respectively, ${ }^{15}$ findings different from ours, where the average hospitalization time according to the affected organ is greater, especially in pulmonary CE with an average of 19 (4-249) days.

However, it must be clarified that taking only the post-surgical times, there are no significant differences according to the affected organ. This reflects that the number of days of total hospitalization is over estimated because there are various conditions that prolong the total stay of the affected, such as the delay in the scheduling dates for surgical intervention in those patients who are derived from faraway places, or the time it takes to make the confirmatory diagnosis in those who were admitted for emergencies to the hospital. This last factor has relevance in the medical decision to use a certain surgical technique. Our findings show that the type of surgery is an important factor that prolongs the number of days of post-surgical hospitalization, similar to that reported by Ko-Iam $\mathrm{W}$ et al. ${ }^{27}$ who point out that even laparoscopic techniques during the procedure play a relevant factor that increases the length of hospital stay. ${ }^{27}$

In relation to the previously discussed, it is necessary to highlight that the findings published by various authors, point to the complication of the hydatid cyst as an important factor in the number of days of hospitalization, but using bivariate models, which could have overestimated the association due effect of possible confounders. In this sense, our findings value this association with a multivariate model, in which given the large dispersion of data, we used the negative binomial regression model,,$^{28}$ that according to recent publications, is more robust than the classic Poisson models that consider hospitalization time as a counting variable. ${ }^{29}$

Another important aspect to consider is in relation to post-surgical prophylaxis with albenzadole to reduce the risk of reinfection which can range from 4.6 to $22 \%{ }^{30}$ Our findings suggest that its administration is a factor that significantly decreases the number of 
days of hospitalization in those operated on and should be considered a mandatory aspect in all those who are scheduled for surgery, even more when it is evident that less than half received prophylaxis postsurgical However, the implementation of a drug monitoring and monitoring system should be considered in order to avoid hepatotoxicity, which has already been reported in several studies. ${ }^{31,32}$ In this sense, it is a priority to incorporate methodologies that are fast and reliable for the quantification of albendazole and its metabolites in biological matrices ${ }^{33,34}$ also considering that the dose administered post-surgery is high. ${ }^{35,36}$

The limitations of the present investigation are related to the absence of evaluation of variables such as the patient's nutritional status, as well as the duration of surgery in CE. Several studies have suggested that nutritional status plays a fundamental role in the length of hospital stay of patients who undergo surgery $(\mathrm{RR}=2.5[1.1-5.8]),{ }^{37}$ to such an extent that even the mortality rate in these risk groups increases significantly. ${ }^{38}$ Regarding the time of surgery, it could also generate variation in the number of days of hospitalization, especially in cases of CE complication, and in patients who have co-morbid states as part of their health history. Radical or conservative surgery has very variable times that can range from 3-8 hours,${ }^{39}$ and in general, the increase in the duration of a surgical procedure is directly related to the number of days of post-surgical hospitalization..$^{40}$ Neither data could be obtained that evidences the types of ruptures of the hepatic hydatid cyst, as for example, the intrabiliary rupture (with manifestation of jaundice in the patient and characteristic of ascending cholangitis), occult cistobiliary communication, rupture contained within the cyst or peritoneal rupture with risk of anaphylactic shock. In the case of pulmonary hydatid cyst, the types of rupture such as that occurring in the pleural cavity or bronchi were not recorded. ${ }^{19}$

\section{Conclusion}

In conclusion, we can state that the complication of $\mathrm{CE}$ is not significantly associated with the number of days of post-surgical hospitalization; however, post- surgical prophylactic anthelminthic treatment is significant in reducing the number of days of hospitalization, and in that sense, future research should include this aspect as a potential factor associated with hospitalization time in surgically treated patients.

\section{Acknowledgements}

To the Global Health Center of the Universidad Peruana Cayetano Heredia, for having provided the database for its secondary analysis.

\section{Funding source}

Training grant D43 TW007393 awarded by the Fogarty International Center of the US National Institutes of Health.

\section{Conflicts of interest}

The authors declare no conflicts of interest in the preparation or publication of this artic

\section{References}

1. Brunetti E, Garcia HH, Junghanss T, et al. Cystic Echinococcosis: Chronic, Complex, and Still Neglected. PLOS Neglected Tropical Diseases. 2011;5(7):e1146.

2. Eckert J, Deplazes P. Biological, Epidemiological, and Clinical
Aspects of Echinococcosis, a Zoonosis of Increasing Concern. Clinical Microbiology Reviews. 2004;17(1):107-135.

3. Gavidia CM, Gonzalez AE, Zhang W, et al. Diagnosis of Cystic Echinococcosis, Central Peruvian Highlands. Emerging Infectious Diseases. 2008;14(2):260-266.

4. Salgado S SL, Cabrera R. Características clínicas y epidemiológicas de la equinococosis quística registradas en un área endémica en los andes centrales del Perú (1991-2002). Neotrop Helminthol. 2007;1(2):69-84.

5. Moro PL, McDonald J, Gilman RH, et al. Epidemiology of Echinococcus granulosus infection in the central Peruvian Andes. Bulletin of the World Health Organization. 1997;75(6):553-551.

6. Moro PL, Lopera L, Cabrera M, et al. Short report: endemic focus of cystic echinococcosis in a coastal city of Peru. Am J Trop Med Hyg. 2004;71(3):327-329.

7. Santivañez SJ, Gutierrez AM, Rosenzvit MC, et al. Human Hydatid Disease in Peru Is Basically Restricted to Echinococcus granulosus Genotype G1. The American journal of tropical medicine and hygiene. 2008;79(1):89-92.

8. Brunetti E, Kern P, Vuitton DA. Expert consensus for the diagnosis and treatment of cystic and alveolar echinococcosis in humans. Acta Tropica. 2010;114(1):1-16.

9. Junghanss T, da Silva AM, Horton J, et al. Clinical Management of Cystic Echinococcosis: State of the Art, Problems, and Perspectives. The American Journal of Tropical Medicine and Hygiene. 2008;79(3):30111.

10. Smego RA Jr, Sebanego P. Treatment options for hepatic cystic echinococcosis. International Journal of Infectious Diseases. 2005;9(2):69-76.

11. Chautems R, Buhler LH, Gold B, et al. Surgical management and longterm outcome of complicated liver hydatid cysts caused by Echinococcus granulosus. Surgery. 2005;137(3):312-316.

12. He YB, Yao G, Tuxun T, et al. Efficacy of radical and conservative surgery for hepatic cystic echinococcosis: a meta-analysis. Int J Clin Exp Med. 2015;8(5):7039-7048.

13. Pandey A, Chandra A, Masood S. Abdominal echinococcosis: outcomes of conservative surgery. Transactions of the Royal Society of Tropical Medicine and Hygiene. 2014;108(5):264-268.

14. Mastrandrea S, Stegel G, Piseddu T, et al. A retrospective study on burden of human echinococcosis based on Hospital Discharge Records from 2001 to 2009 in Sardinia, Italy. Acta Trop. 2012;123(3):184-189.

15. Herrador Z, Siles-Lucas M, Aparicio P, et al. Cystic Echinococcosis Epidemiology in Spain Based on Hospitalization Records, 1997-2012. PLOS Neglected Tropical Diseases. 2016;10(8):e004942.

16. Craig PS, McManus DP, Lightowlers MW, et al. Prevention and control of cystic echinococcosis. The Lancet Infectious Diseases. 2007;7(6):385-94.

17. Chebli H, Laamrani El Idrissi A, Benazzouz M, et al. Human cystic echinococcosis in Morocco: Ultrasound screening in the Mid Atlas through an Italian-Moroccan partnership. PLOS Neglected Tropical Diseases. 2017;11(3):e0005384.

18. Akcan A, Sozuer E, Akyildiz H, et al. Predisposing factors and surgical outcome of complicated liver hydatid cysts. World Journal of Gastroenterology: WJG. 2010;16(24):3040-3048.

19. Kuzucu A, Soysal O, Ozgel M, et al. Complicated hydatid cysts of the lung: clinical and therapeutic issues. The Annals of thoracic surgery. 2004;77(4):1200-1204. 
20. Dopchiz MC, Elissondo MC, Rossin MA, et al. Hydatidosis cases in one of Mar del Plata City hospitals, Buenos Aires, Argentina. Revista da Sociedade Brasileira de Medicina Tropical. 2007;40:635-639.

21. Del Carpio M, Hugo Mercapide C, Salvitti JC, et al. Early Diagnosis, Treatment and Follow-Up of Cystic Echinococcosis in Remote Rural Areas in Patagonia: Impact of Ultrasound Training of Non-Specialists. PLOS Neglected Tropical Diseases. 2012;6(1):e1444.

22. Fano P HH, Falcón N. Costos de la Atención de Pacientes con Equinococosis Quística Humana en un hospital de Niños en Lima-Perú, Periodo 2006-2010. Salud y Tecnología Veterinaria. 2014;2(1):63-70.

23. Fica A, Weitzel T. Gastos hospitalarios en pacientes con fascioliasis en fase aguda, hidatidosis de tratamiento quirúrgico y neurocisticercosis en un hospital general en Chile. Revista chilena de infectología. 2014;31:406-410.

24. Signorini DF. Sample size for Poisson regression. Biometrika. $1991 ; 78(2): 446-450$.

25. Thomas SD, Hathaway DK, Arheart KL. Face validity. Western journal of nursing research. 1992;14(1):109-112.

26. Sorin Berbece CB, Silviu Ciurea, Victor Tomulescu. Surgical Treatment of Complicated Liver Echinococcosis - Our Experience with 184 Cases in 10 Years. J Transl Med Res. 2016;21(1):42-46.

27. Ko-Iam W, Sandhu T, Paiboonworachat S, et al. Predictive Factors for a Long Hospital Stay in Patients Undergoing Laparoscopic Cholecystectomy. International journal of hepatology. 2017;2017:5497936.

28. Carter EM, Potts HWW. Predicting length of stay from an electronic patient record system: a primary total knee replacement example. $B M C$ Medical Informatics and Decision Making. 2014;14:26.

29. Weaver CG, Ravani P, Oliver MJ, et al. Analyzing hospitalization data: potential limitations of Poisson regression. Nephrology Dialysis Transplantation. 2015;30(8):1244-1249.

30. Prousalidis J, Kosmidis C, Anthimidis G, et al. Postoperative recurrence of cystic hydatidosis. Canadian Journal of Surgery. 2012;55(1):15-20.
31. Choi GY, Yang HW, Cho SH, et al. Acute Drug-Induced Hepatitis Caused by Albendazole. Journal of Korean Medical Science. 2008;23(5):903905

32. Shah C, Mahapatra A, Shukla A, Bhatia S. Recurrent acute hepatitis caused by albendazole. Trop gastroenterol. 2013;13;34(1):38-39.

33. Prochazkova A, Chouki M, Theurillat $\mathrm{R}$, et al. Therapeutic drug monitoring of albendazole: determination of albendazole, albendazole sulfoxide, and albendazole sulfone in human plasma using nonaqueous capillary electrophoresis. Electrophoresis. 2000;21(4):729-736.

34. Wojnicz A, Cabaleiro-Ocampo T, Roman-Martinez M, et al. A simple assay for the simultaneous determination of human plasma albendazole and albendazole sulfoxide levels by high performance liquid chromatography in tandem mass spectrometry with solid-phase extraction. Clinica chimica acta; international journal of clinical chemistry. 2013;426:58-63.

35. Moroni S, Moscatelli G, Bournissen FG, et al. Abdominal Cystic Echinococcosis Treated with Albendazole. A Pediatric Cohort Study. PLOS ONE. 2016;11(9):e0160472.

36. Shams Ul B, Arif SH, Malik AA, et al. Role of Albendazole in the Management of Hydatid Cyst Liver. Saudi $J$ Gastroenterol. 2011;17(5):343-347.

37. Leandro-Merhi VA, Aquino JLBd, Chagas JFS. Nutrition Status and Risk Factors Associated With Length of Hospital Stay for Surgical Patients. Journal of Parenteral and Enteral Nutrition. 2011;35(2):241-248.

38. Hiesmayr M, Schindler K, Pernicka E, et al. Decreased food intake is a risk factor for mortality in hospitalised patients: the NutritionDay survey 2006. Clinical nutrition (Edinburgh, Scotland). 2009;28(5):484-491.

39. Martel G, Ismail S, Bégin A, et al. Surgical management of symptomatic hydatid liver disease: experience from a Western centre. Canadian Journal of Surgery. 2014;57(5):320-326.

40. Jarab F, Omar E, Bhayat A, et al. Duration of Hospital Stay Following Orthognathic Surgery at the Jordan University Hospital. Journal of Maxillofacial \& Oral Surgery. 2012;11(3):314-318. 